\title{
Answer to quiz, discussion, and conclusion
}

\author{
A.G. B. A. K. Jayarathna, S. M. Fernandopulle, Department of Pathology, North Colombo Teaching \\ Hospital, Ragama, Sri Lanka
}

\section{Answer to quiz}

The smears were sparsely cellular and showed flat sheets, clusters and singly scattered oncocytic cells. The constituent cells were large and had central round nuclei and abundant dense eosinophilic cytoplasm. Lymphocytes and nuclear debris were not seen in the background. Scattered unremarkable salivary acinar cells were identified admixed with oncocytic cells.

FNAC was concluded as a benign, oncocyte predominant smear. The possibility of an oncocytic neoplasm cannot be ruled out and histological assessment was recommended for a definite diagnosis.

Resected left parotidectomy specimen comprised multiple pieces of tissue measuring $70 \times 55 \times 30 \mathrm{~mm}$ in aggregate. The cut surface showed vague yellow coloured nodules ranging from 3 to $10 \mathrm{~mm}$. Encapsulated lesions, hemorrhages or necrosis were not identified.

Microscopy revealed multiple, irregular, unencapsulated nodules scattered within the normal salivary acini (Figures 1 \& 3). The nodules were composed of densely packed tubuloacinar structures arranged in back to back manner and sheets of round to polygonal cells with central uniform round nuclei and eosinophilic cytoplasm (Figures 2\& 3). Cellular or nuclear pleomorphism, necrosis, vascular invasion or encapsulated lesions were not identified.

Histology was concluded as nodular oncocytic hyperplasia of the parotid gland. There were no recurrences on follow up.

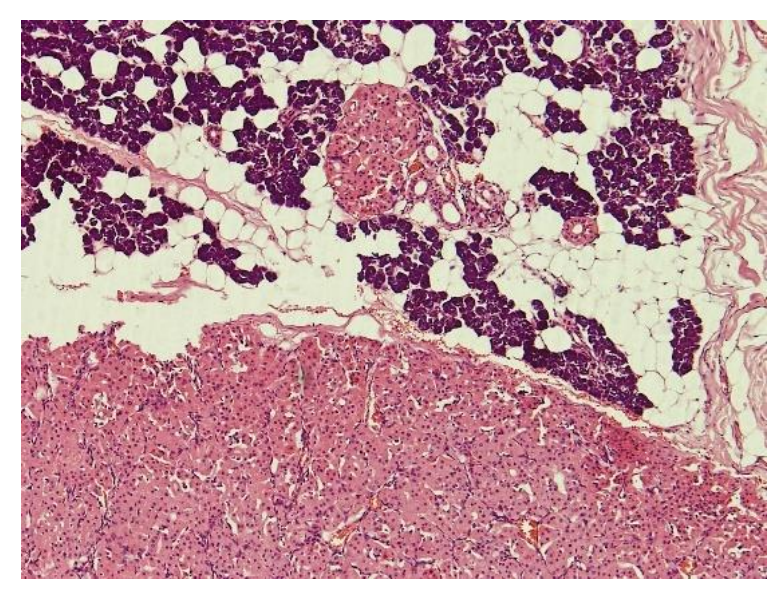

Figure 1: Multiple unencapsulated nodules of oncocytic cells in the parotid gland (H\&E x 40).

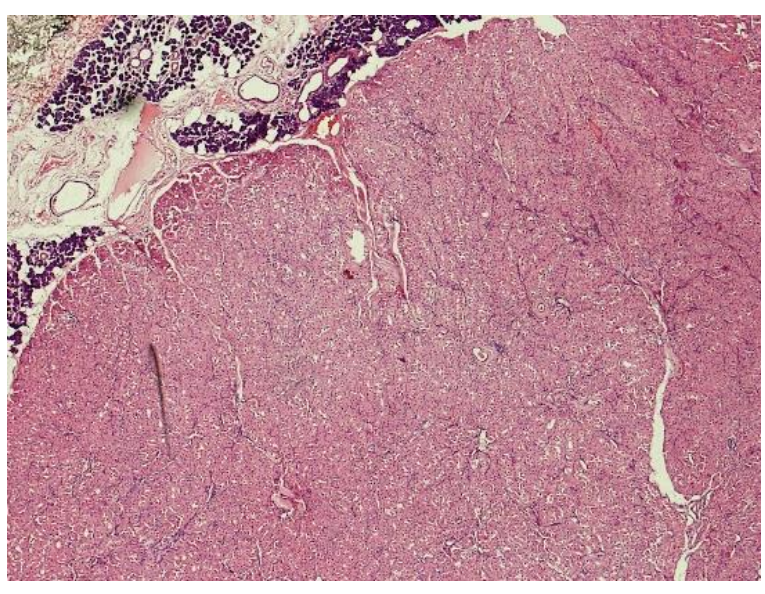

Figure 2: Non encapsulated nodules composed of sheets of oncocytic cells (H\&E X 200).

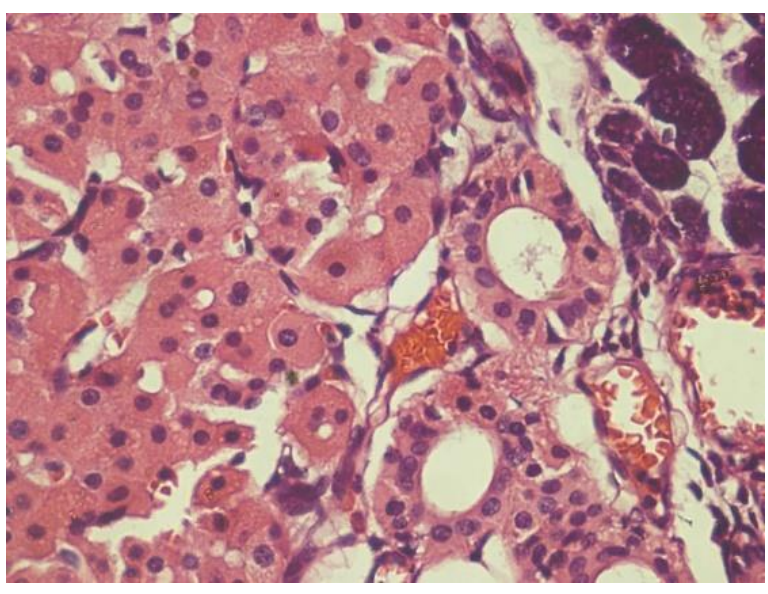

Figure 3: Normal salivary ducts entrapped within the oncocytic cell nodules (H\&E X 400) 


\section{Discussion}

FNAC is a valuable tool in the diagnosis of salivary gland neoplasms[1]. The oncocytic cells show abundant densely granular eosinophilic cytoplasm and central round nuclei with a distinct nucleolus in cytology [2]. As a variety of neoplastic and non-neoplastic lesions in the salivary glands harbor oncocytes, interpretation of FNAC with oncocytes is challenging. These lesions include non-neoplastic entities, benign and malignant tumours. Nodular oncocytic hyperplasia and oncocytic metaplasia associated with ageing are non-neoplastic lesions. Benign tumours include oncocytoma, Warthins tumour and pleomorphic adenoma with oncocytic features. The malignant tumours are oncocytic carcinoma, acinic cell carcinoma, oncocytic variant of mucoepidermoid carcinoma(MECA) salivary duct carcinoma[2], mammary analogue secretory carcinoma, papillary oncocytic cystadenocarcinoma and metastatic deposits of a carcinoma[3]. Although some of these tumours show characteristic features enabling differentiation from non-neoplastic lesions in cytology, some show overlapping features. Therefore, differentiating salivary oncocytic lesions need careful interpretation of cytology and clinicopatholocial and radiological correlation [4].

Nodular oncocytic hyperplasia $(\mathrm{NOH})$ is a rare salivary gland lesion characterized by multiple, non-neoplastic, nodular proliferations of oncocytes. Cytology can mimic a range of lesions with oncocytes in salivary glands [5].

The term Nodular Oncocytic Hyperplasia was first described by Schwartz and Felman as a non-neoplastic oncocytic lesion of the salivary gland [7]. The aetiology of $\mathrm{NOH}$ is largely unknown and recent evidence suggests that HPV infection and mutations in the mitochondrial DNA may play a role. These lesions occur exclusively in the parotid gland and $40 \%$ are bilateral.

It commonly occurs in females of sixth decade and presents as a long standing painless swelling of the parotid gland. Radiology shows multiple hypoechoic areas. FNAC of $\mathrm{NOH}$ comprises flat sheets of oncocytes and salivary acini in a clean background. These cellular features are similar to that of oncocytoma. Oncocytoma is a rare salivary gland tumour composed predominantly of oncocytes and cytosmears comprise oncocytes with minimal atypia, arranged in sheets, papillary structures and single cells [1]. Hence it is very difficult to differentiate $\mathrm{NOH}$ from oncocytoma with cytology alone. However, on imaging oncocytoma appears as a well-defined mass with homogenous enhancement. Whereas $\mathrm{NOH}$ shows multiple hypoechoic areas. Therefore, clinical and radiological correlation is mandatory in differentiating these lesions preoperatively [6]. Histologically, the lesions of $\mathrm{NOH}$ are formed of variable sized nodules, comprising monomorphic oncocytes with small round nuclei and eosinophilic granular cytoplasm. These nodules are non-encapsulated and entrapped in normal salivary acini [7]. The oncocyte like cells are diffusely positive for cytokeratin and strongly positive for mitochondrial antibodies.

Warthin's tumor is the most common salivary gland tumor that shows abundant oncocytic cells in FNAC. The aspiration comprises murky fluid and smears contain sheets of oncocytic cells with minimal atypia. The characteristic feature helpful in differentiating this from other oncocytic lesions is the presence of lymphocyte rich background [4].

Pleomorphic adenoma with oncocytic changes is another differential diagnosis for oncocytic cell rich cytology of the parotid gland [8]. Although eventual oncocytic changes are common in myoepithelial cells of pleomorphic adenoma, extensive oncocytic differentiation is rare. The myoepithelial cells with oncocytic change are polygonal to spindle-shaped and the cytoplasm is granular. Cytology also shows epithelial cells, myoepithelial cells and fibrillary myxoid material in the background that aid to differentiate this lesion from other oncocytic lesions[8].

Mucoepidermoid carcinoma (MECA) when > $60 \%$ of the tumour cells show oncocytic changes is classified as oncocytic variant of MECA [9]. The cytology of classic MECA shows debris and mucus, with epithelial cells that appear trapped within the mucus and both 
glandular mucin secreting cells and squamous cells are present[9]. However, the cytology of oncocytic variant of MECA, may comprise exclusively of oncocytic cells in a background of cellular debris devoid of mucous secreting or squamous cells mimicking $\mathrm{NOH}$ or other tumours with oncocytes.

Oncocytic carcinoma is an extremely rare salivary gland malignancy and exclusively composed of atypical oncocytic cells. It is very difficult to diagnose on cytology alone[10]. However, the possibility of oncocytic carcinoma should be raised if there is evidence of nuclear pleomorphism, frequent mitoses with atypical forms and necrosis[5].

Occasionally tumour cells of acinic cell carcinoma and salivary duct carcinoma may mimic oncocytes in cytology smears $[2,6]$. However, other characteristic cytomorphology features of these tumours are helpful in differential diagnosis.

One percent of the salivary gland tumours are metastases. Some of these tumours, especially metastatic oncocytic renal cell carcinoma should be considered in the differential diagnosis although a remote possibility [3].

\section{Conclusion}

Accurate interpretation of preoperative FNAC is mandatory in managing patients with salivary gland oncocytic lesions. As there are no established cytological criteria to differentiate these rare non- neoplastic oncocytic lesions from oncocytic tumours such cytological diagnoses pause definite challenge. Correlation of cytology findings with the clinical picture and imaging can minimize this problem. Histological assessment is the gold standard for the diagnosis of salivary oncocytic lesions. Further studies will be helpful in identifying specific cytological features unique to these lesions.

\section{References}

1. Chakrabarti I, Ghosh N, Basu A. Oncocytic lesion of parotid gland: A dilemma for cytopathologists. J Cytol
[Internet]. 2012 [cited 2021 Jul 25];29(1):80. Available from: http://www.jcytol.org/text.asp?2012/29 /1/80/93236

2. Moriki T, Ueta S, Takahashi T, Mitani M, Ichien M. Salivary duct carcinoma: Cytologic characteristics and application of androgen receptor immunostaining for diagnosis. Cancer [Internet]. 2001 Oct 15 [cited 2021 Jul 25];93(5):344-50. Available from: https://onlinelibrary.wiley.com/doi/10.1 002/cncr.9050

3. Majewska H, Skálová A, Radecka K, Stodulski D, Hyrcza M, Stankiewicz C, et al. Renal clear cell carcinoma metastasis to salivary glands - a series of 9 cases: clinico-pathological study. Pol J Pathol [Internet]. 2016 [cited 2021 Jul 25];1:39-45. Available from: http://www.termedia.pl/doi/10.5114/pj p. 2016.59475

4. Bajaj P, Garg D, Sabharwal R, Gautam S. Fine Needle Aspiration Cytology in Warthin's Tumor: A Diagnostic tool. Diagn Pathol Open Access [Internet]. 2016 [cited 2021 Jul 25];01(01). Available from: https://www.omicsonline.org/openaccess/fine-needle-aspiration-cytologyin-warthins-tumor-a-diagnostic-toolDPO-1000102. . php?aid $=63766$

5. Politi $M$, Toro C, Cian R, Robiony $M$, Zerman N. Multifocal adenomatous oncocytic hyperplasia of the parotid gland. Oral Oncol Extra [Internet]. 2005 Sep [cited 2021 Jul 25];41(8):183-7. Available from: https://linkinghub.elsevier.com/retrieve /pii/S1741940905000373

6. Berezowski K. Acinic Cell Carcinoma:: Cytologic Features and Diagnostic Pitfalls. Pathol Case Rev [Internet]. 2004 Nov [cited 2021 Jul 25];9(6):231-5. Available from: http://journals.Iww.com/00132583200411000-00002 
7. Kinoshita $Y$, Harada $H$, Kobayashi TK, Yoshizawa K, Yuri T, Takasu K, et al. Multifocal Adenomatous Oncocytic Hyperplasia of the Parotid Gland. Case Rep Oncol [Internet]. 2014 Dec 5 [cited 2021 Jul 25];7(3):819-24. Available from:

https://www.karger.com/Article/FullTex t/370146

8. Handa U, Dhingra N, Chopra R, Mohan H. Pleomorphic adenoma: Cytologic variations and potential diagnostic pitfalls. Diagn Cytopathol [Internet]. 2009 Jan [cited 2021 Jul 25];37(1):11-5. Available from: https://onlinelibrary.wiley.com/doi/10.1 002/dc.20951

9. Krishnanand $G$, Kaur $M$, Rao RV, Monappa V. Oncocytic variant of mucoepidermoid carcinoma of submandibular gland: an unusual clinical and morphological entity. Indian J Pathol Microbiol. 2007 Jul;50(3):538-40.

10. Pathak $R$, Prasad $K$, Rauniyar $S$, Pudasaini S, Pande K, Koirala $S$, et al. Fine needle aspiration cytology of head and neck lesions and its correlation with histopathology. J Pathol Nepal. 2016 Sep 24;6:985. 